\title{
Correction on Religion Wise Differences in Female's Attitude towards Role Portrayal of Women in Tv Advertisements
}

\section{Mohd. Tariq}

Aligarh Muslim University, INDIA

Mohd. Afaq Khan

Aligarh Muslim University, INDIA

Vandana Singh

Gurukul Kangri University, INDIA

Priya Singh

Gurukul Kangri University, INDIA

Issue Date:

Original Paper:
19 January 2019

Religion Wise Differences in Female's Attitude towards Role Portrayal of Women in Tv Advertisements

Online Journal of Communication and Media Technologies (2018), 8(1), 112-129.

This document lists errors found in the paper.

1. In Authors and affiliations Section, change author name "Mohd. Tariqa" to "Mohd. Tariq"
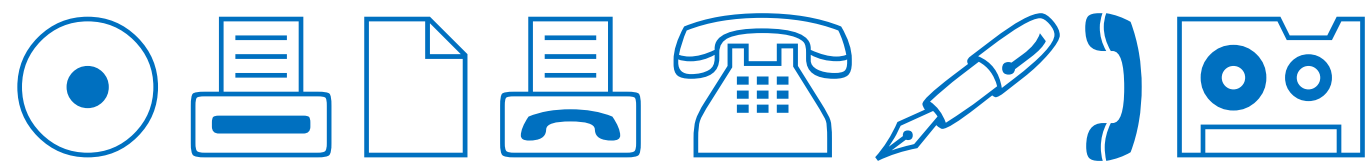